\title{
Ulcerative Colitis-Associated Colorectal Adenocarcinoma
}

National Cancer Institute

\section{Source}

National Cancer Institute. Ulcerative Colitis-Associated Colorectal Adenocarcinoma. NCI Thesaurus. Code C96496.

A colorectal adenocarcinoma that develops in patients with a history of ulcerative colitis. Such carcinomas are usually multiple and flat. Histologically, they are usually mucinous or signet-ring cell type. 